\title{
Solution-Processible n-Channel Organic Field-Effect Transistors Based on Dicyanomethylene-substituted Terthienoquinoid Derivative
}

Sayuri Handa, Eigo Miyazaki, Kazuo Takimiya, and Yoshihito Kunugi

\section{Contents}

1. Synthesis

2. NMR spectra of 3

3. Physicochemical properties (UV-vis, DSC, and CV)

4. XRDs and UV-vis spectra of thin films

5. Device fabrications and evaluations

6. References

\section{Synthesis}

General: All chemicals and solvents are of reagent grade unless otherwise indicated. Toluene and THF were purified by standard distillation procedures prior to use. 1,3-Dibromo-5,5-bis(hexyloxymethyl)cyclopenta[c]thiophene ${ }^{\mathrm{S} 1}$ was synthesized according to the reported procedures. Melting points were uncorrected. Nuclear magnetic resonance spectra were obtained in deuterated chloroform with a JEOL Lambda 400 spectrometer operating at $400 \mathrm{MHz}$ for ${ }^{1} \mathrm{H}$ with TMS as internal reference; chemical shifts $(\delta)$ are reported in parts per million. NOESY spectra were obtained in deuterated dichloromethane with a Varian Mercury-300 spectrometer operating at $300 \mathrm{MHz}$. EI-MS spectra were obtained on a Shimadzu QP-5050A spectrometer using an electron impact ionization procedure $(70 \mathrm{eV})$. The molecular ion peaks of the sulfur- and/or bromine- containing compounds showed a typical isotopic pattern, and all the mass peaks are reported based on ${ }^{32} \mathrm{~S}$ and ${ }^{79} \mathrm{Br}$.

\section{2,1';3',2'-Dithienyl-5',5'-bis(hexyloxymethyl)cyclopenta[c]thiophene (4)}

A solution of 1,3-dibromo-5,5-bis(hexyloxymethyl)cyclopenta[c]thiophene $(1.26 \mathrm{~g}, 2.48 \mathrm{mmol})^{\mathrm{S} 1}$ and 2-tributhylstannylthiophene $(2.22 \mathrm{~g}, 5.96 \mathrm{mmol})$ in dry toluene $(40 \mathrm{~mL})$ was dearated by argon stream for $30 \mathrm{~min} . \mathrm{Pd}\left(\mathrm{PPh}_{3}\right)_{4}(143 \mathrm{mg}, 0.12 \mu \mathrm{mol})$ was added to the solution, and the resulting mixture was refluxed for $20 \mathrm{~h}$ in dark. After cooling, the mixture was filtered through a Celite pad, and the filtrate was concentrated in vacuo to give a yellow solid. The crude product was purified by column chromatography on silica gel eluted with hexane-dichloromethane $(2: 1, v / v)$ to give a yellow solid $\left(R_{f}=0.4\right)$. Analytical sample of $\mathbf{4}$ was obtained as pale yellow needles by recrystallization from ethanol (648 $\mathrm{mg}, 54 \%)$. 
mp 65-66 ${ }^{\circ} \mathrm{C} ;{ }^{1} \mathrm{H}$ NMR (400 MHz, $\left.\mathrm{CDCl}_{3}\right) \delta 0.87(\mathrm{t}, J=6.8 \mathrm{~Hz}, 6 \mathrm{H}), 1.25-1.52(\mathrm{~m}, 12 \mathrm{H})$, 1.53-1.58 (m,4H), 2.75 (s, 4H), 3.41-3.44 (m, 8H), 7.01 (dd, $J=3.6,5.1 \mathrm{~Hz}, 2 \mathrm{H}), 7.10$ (dd, $J=$ 1.0, $3.6 \mathrm{~Hz}, 2 \mathrm{H}), 7.21$ (dd, $J=1.0,5.1 \mathrm{~Hz}, 2 \mathrm{H}) ;{ }^{13} \mathrm{C} \mathrm{NMR}\left(100 \mathrm{MHz}, \mathrm{CDCl}_{3}\right) \delta 14.0,22.6,25.8$, 29.5, 31.6, 34.4, 55.2, 71.5, 73.8, 123.2, 124.1, 125.1, 127.6, 137.2, 143.8; MS (EI) $\mathrm{m} / \mathrm{z}=516$ $\left(\mathrm{M}^{+}\right)$; Anal. Calcd for $\mathrm{C}_{29} \mathrm{H}_{40} \mathrm{O}_{2} \mathrm{~S}_{3}$ : C, 67.39; H, 7.80; Found: C, 67.31; H, 7.63.

\section{5,5"'-Dibromo-2,1';3',2"'-dithienyl-5',5'-bis(hexyloxymethyl)cyclopenta[c]thiophene (5)}

To an ice-cooled solution of 4 (158 $\mathrm{mg}, 0.23 \mathrm{mmol})$ in chloroform $(20 \mathrm{~mL})$ was added $\mathrm{N}$-bromosuccinimide (83 $\mathrm{mg}, 0.46 \mathrm{mmol}$ ), and the resulting mixture was stirred at rt for $5 \mathrm{~h}$. The reaction was quenched by an addition of saturated aqueous sodium carbonate solution (10 $\mathrm{mL})$, and the mixture was extracted with chloroform $(50 \mathrm{~mL} \times 3)$. The combined extract was washed with brine $(100 \mathrm{~mL})$, dried $\left(\mathrm{MgSO}_{4}\right)$, and concentrated in vacuo. The oily residue was chromatographed on silica gel eluted with hexane-dichloromethane $(2: 1, \mathrm{v} / \mathrm{v})$ to give a yellow solid $\left(R_{\mathrm{f}}=0.5\right)$. Recrystallization from acetonitrile gave analytical pure 3 as yellow needles (236 mg, 88\%).

mp 58-59 ${ }^{\circ} \mathrm{C} ;{ }^{1} \mathrm{H}$ NMR (400 MHz, $\left.\mathrm{CDCl}_{3}\right) \delta 0.91$ (t, $\left.J=6.4 \mathrm{~Hz}, 6 \mathrm{H}\right), 1.26-1.38(\mathrm{~m}, 12 \mathrm{H})$, 1.53-1.56 (m, 4H), 2.73 (s, 4H), 3.40-3.43 (m, 8H), 6.82 (d, $J=3.6 \mathrm{~Hz}, 2 \mathrm{H}), 6.97$ (d, $J=3.6 \mathrm{~Hz}$, 2H); ${ }^{13} \mathrm{C}$ NMR (100 MHz, $\left.\mathrm{CDCl}_{3}\right) \delta$ 14.0, 22.6, 25.8, 29.4, 31.6, 34.2, 55.4, 71.4, 73.7, 110.9, 123.2, 124.5, 130.4, 138.5, 144.2; MS (EI) $\mathrm{m} / \mathrm{z}=672\left(\mathrm{M}^{+}\right)$; Anal. Calcd for $\mathrm{C}_{29} \mathrm{H}_{38} \mathrm{Br}_{2} \mathrm{O}_{2} \mathrm{~S}_{3}$ : C, 51.63; H, 5.68; Found: C, 51.60; H, 5.54.

\section{5,5"-Bis(dicyanomethylene)-5,5"'-dihydro- $\Delta^{2,1 ' ; 3 ', 2 "}$-dithienyl-5',5'-bis(hexyloxymethyl)cyclope nta[c]thiophene (3) ${ }^{\mathrm{S} 2, \mathrm{~S} 3}$}

Sodium hydride (60\% in oil, $71 \mathrm{mg}, 2.96 \mathrm{mmol}$ ) was added into a solution of malononitrile (98 mg, $1.48 \mathrm{mmol})$ in dry THF (20 mL), and the mixture was stirred at $\mathrm{rt}$ for $30 \mathrm{~min}$. After tetrakis(triphenylphosphine)palladium (17 mg, $14.7 \mu \mathrm{mol}$ ) and dppf (17 mg, $30.7 \mu \mathrm{mol}$ ) were added, a solution of 3 (100 mg, $0.15 \mathrm{mmol}$ ) in dry THF (30 mL) was slowly added over a period of $20 \mathrm{~min}$. The mixture was refluxed for $20 \mathrm{~h}$, and then diluted hydrochloric acid ( $2 \mathrm{M}, 30 \mathrm{~mL}$ ) was added with ice-cooling. After stirred for $30 \mathrm{~min}$ under air, the mixture was extracted with chloroform (50 $\mathrm{ml} \times 3)$, and the extracts were combined, washed with brine $(100 \mathrm{~mL})$, and dried $\left(\mathrm{MgSO}_{4}\right)$. After evaporation of the solvent, the residue was purified by column chromatography (silica gel, chloroform, $\mathrm{R}_{\mathrm{f}}=0.5$ ) followed by recrystallization from acetone-acetonitrile to give deep green crystals of 3 (60 mg, 63\%).

mp: $300{ }^{\circ} \mathrm{C}$ (melt with decomposition); ${ }^{1} \mathrm{H} \mathrm{NMR}\left(400 \mathrm{MHz}, \mathrm{CDCl}_{3}\right) \delta 0.87(\mathrm{t}, J=6.8 \mathrm{~Hz}, 6 \mathrm{H}$ ), 1.23-1.34 (m, 12H), 1.53-1.61 (m, 4H), 2.83-2.92 (m, 4H), 3.42-3.46 (m, 8H), 7.21-7.26 (m, 1H), 7.32-7.36 (m, 1H), 7.40-7.43 (m, 1H), 7.52-7.56 (m, 1H); ${ }^{1} \mathrm{H}$ NMR (300 MHz, $\left.\mathrm{CD}_{2} \mathrm{Cl}_{2}\right) \delta 0.86(\mathrm{t}$, 
$J=9.52 \mathrm{~Hz}, 6 \mathrm{H}), 1.24-1.35$ (m, 12H), 1.50-1.59 (m, 4H), 2.86-2.93 (m, 4H), 3.42-3.48 (m, 8H), 7.23-7.25 (m, 1H), 7.32-7.35 (m, 1H), 7.44-7.47 (m, 1H), 7.56-7.59 (m, 1H); MS (EI) m/z = 642 $\left(\mathrm{M}^{+}\right)$; IR (KBr) $2206.8 \mathrm{~cm}^{-1}(\mathrm{CN})$; Anal. Calcd for $\mathrm{C}_{35} \mathrm{H}_{38} \mathrm{~N}_{4} \mathrm{O}_{2} \mathrm{~S}_{3}$ : C, 65.39; H, 5.96; N, 8.71\%; Found: C, 65.44; H, 5.94; N, 8.62\%.

\section{NMR spectra of 3}

Compound 3 was isolated as an isomeric mixture, i.e. cis-cis, cis-trans, trans-trans in terms of the double bonds between three thiophene rings, which gave complicated ${ }^{1} \mathrm{H}$ NMR spectra (Figure S1). In order to define each isomer on the spectra as well as the ratio of each isomer, NOESY measurements were carried out: clear correlated peaks between thiophene $\beta$-protons ( $\delta$ 7.55-7.60, doublet) and methylene protons ( $\delta 2.93$ and 2.88, singlet) in the cyclopentane ring were observed (Figure S2). Therefore, all the signals for $\mathbf{3}$ were assigned as shown in Figure S1, and the ratio of isomers was determined to be cis-cis : cis-trans: trans-trans $=1: 3: 2$. These isomers seem to exist as an equilibrium mixture in solution.

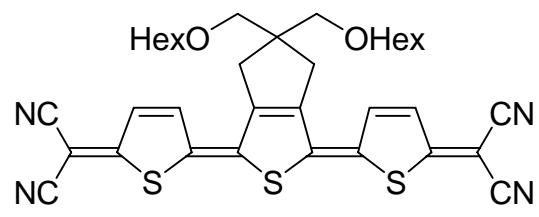

cis-cis

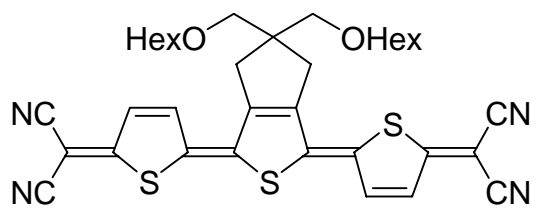

cis-trans

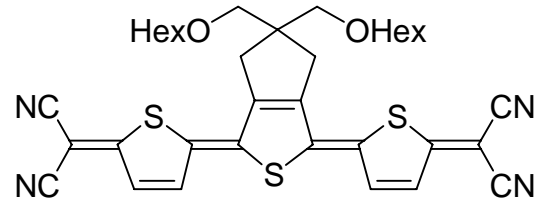

trans-trans 
(a)
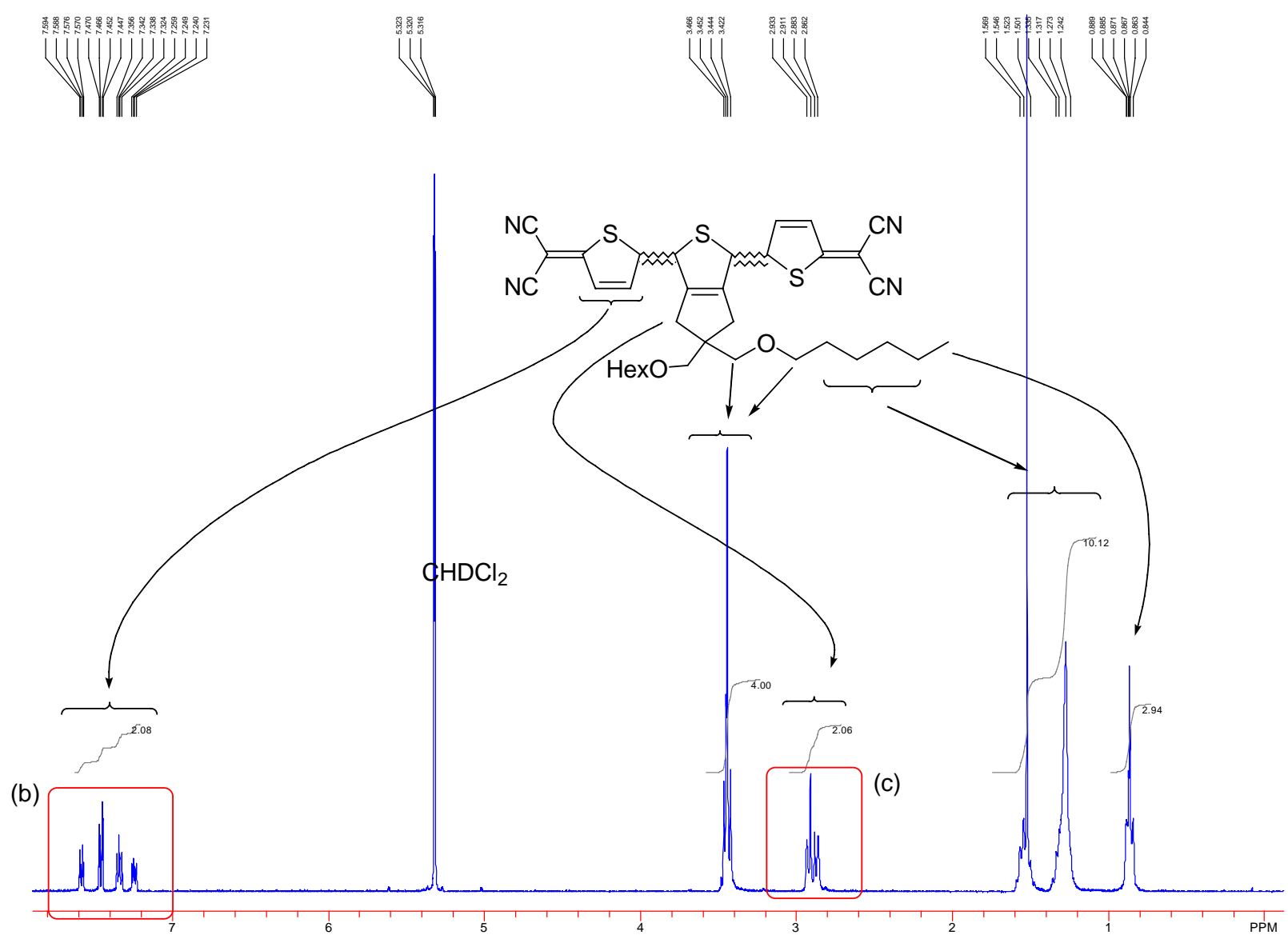

(b)

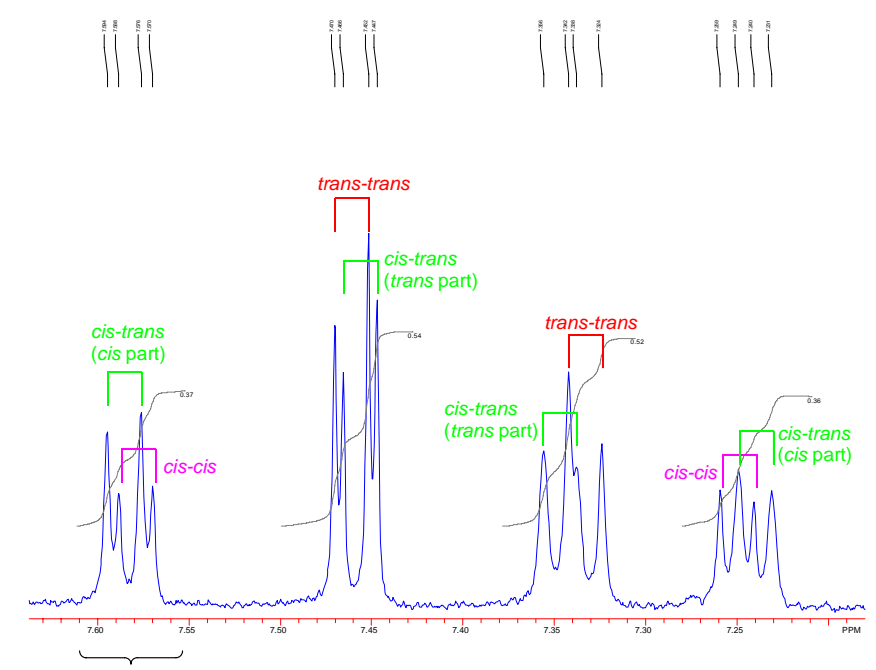

(c)

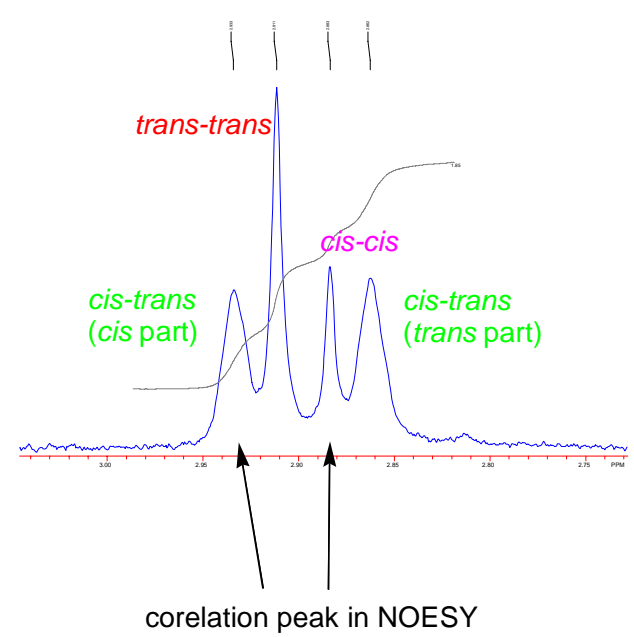

corelation peak in NOESY

Figure S1. ${ }^{1} \mathrm{H}$ NMR spectra of $\mathbf{3}$ in dichloromethane- $d_{2}$. 


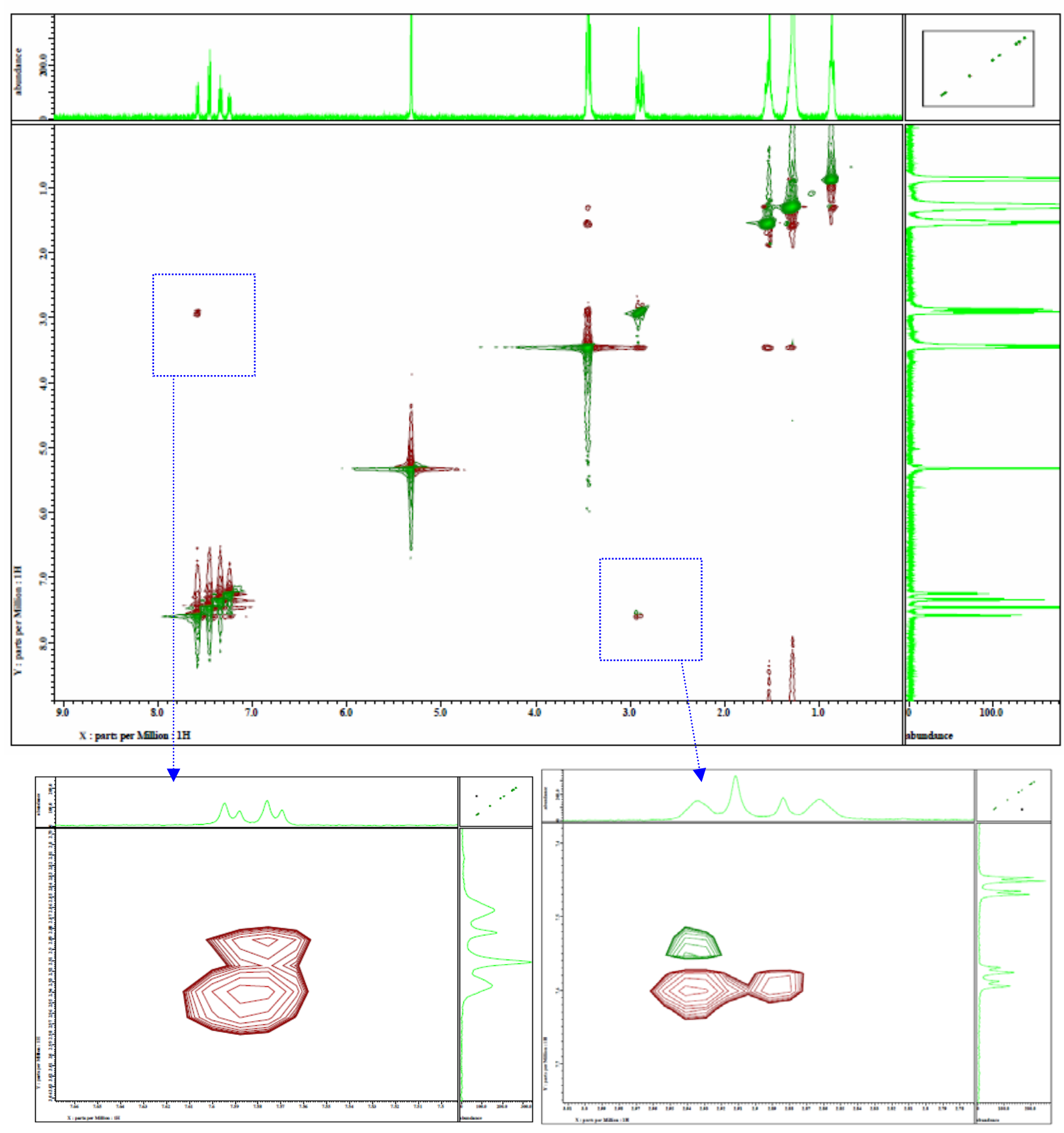

Figure S2. NOESY spectra of 3 in dichloromethane- $d_{2}$. 


\section{Physicochemical properties (UV-vis, DSC, and CV)}

Instruments. UV-vis spectra in chloroform solution was recorded on a Shimadzu UV-3100 spectrometer. Cyclic voltammograms (CVs) were recorded on a Hokuto Denko HA-301 potentiostat and a Hokuto Denko HB-104 function generator in benzonitrile containing tetrabutylammonium hexafluorophosphate $\left(\mathrm{Bu}_{4} \mathrm{NPF}_{6}, 0.1 \mathrm{M}\right)$ as supporting electrolyte at a scan rate of $100 \mathrm{mV} / \mathrm{s}$. Counter and working electrodes were made of $\mathrm{Pt}$, and the reference electrode was $\mathrm{Ag} / \mathrm{AgCl}$. All the potentials were calibrated with the standard ferrocene/ferrocenium redox couple $\left(\mathrm{E}^{1 / 2}=+0.46 \mathrm{~V}\right.$ measured under identical conditions). Differential scanning calorimetry (DSC) was carried out on a Seiko Instruments EXSTAR6000 DSC6200.

Estimation of LUMO energy levels: From the onset of the reduction peak (ca. $-0.1 \mathrm{~V}$ vs. $\mathrm{Ag} / \mathrm{AgCl}$, Figure S4), the LUMO energy level of 3 was estimated to be $4.2 \mathrm{eV}$ below the vacuum level on the premise that the $\mathrm{Fc} / \mathrm{Fc}^{+}$energy level is $4.8 \mathrm{eV}$ below the vacuum level. ${ }^{\mathrm{S}}$

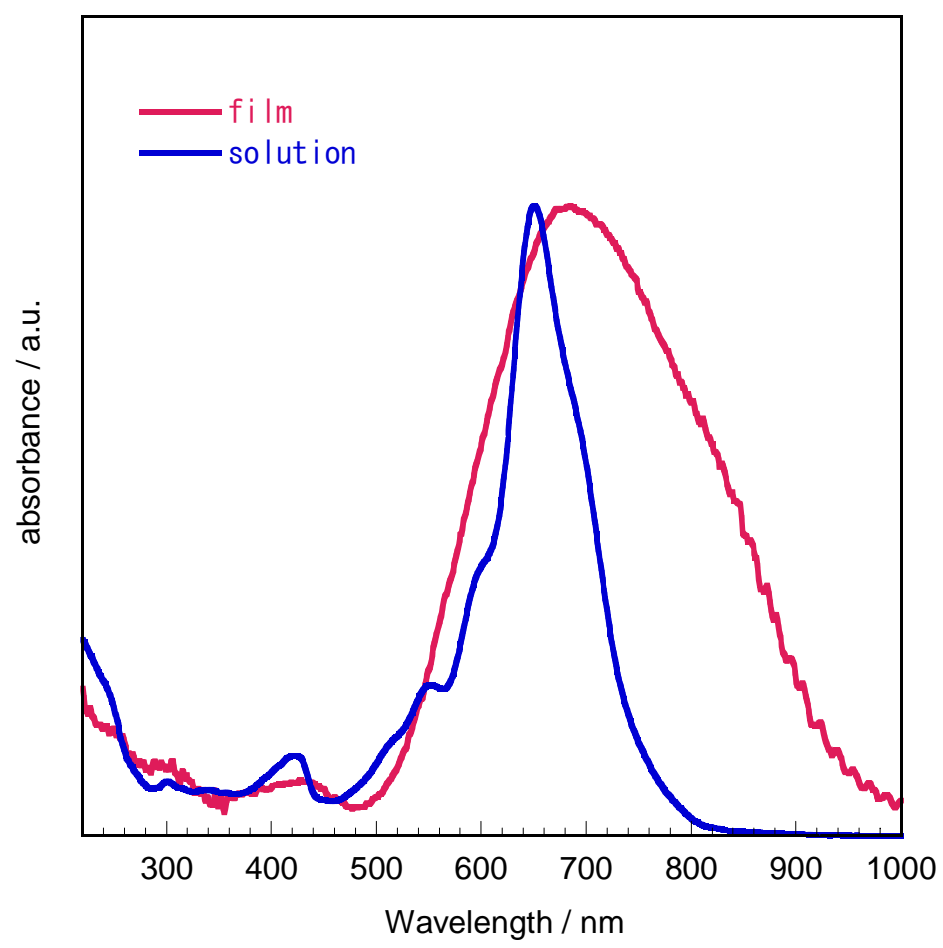

Figure S3. UV-vis spectra of $\mathbf{3}$ in chloroform (blue line) and as-spun film of $\mathbf{3}$ (red line). 


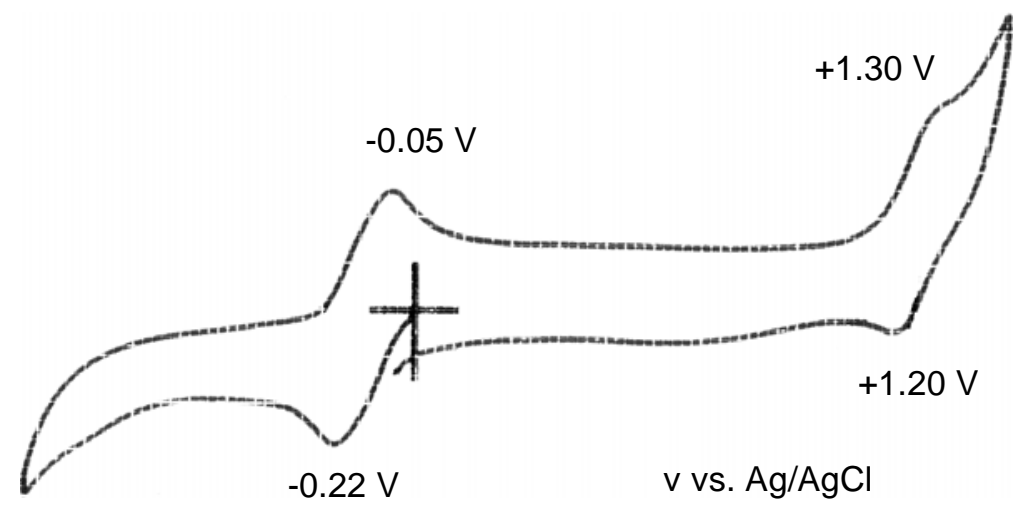

Figure S4. Cyclic voltammogram of 3. Redox potential of $\mathrm{Fc} / \mathrm{Fc}^{+}$under identical conditions was $+0.46 \mathrm{~V}$.

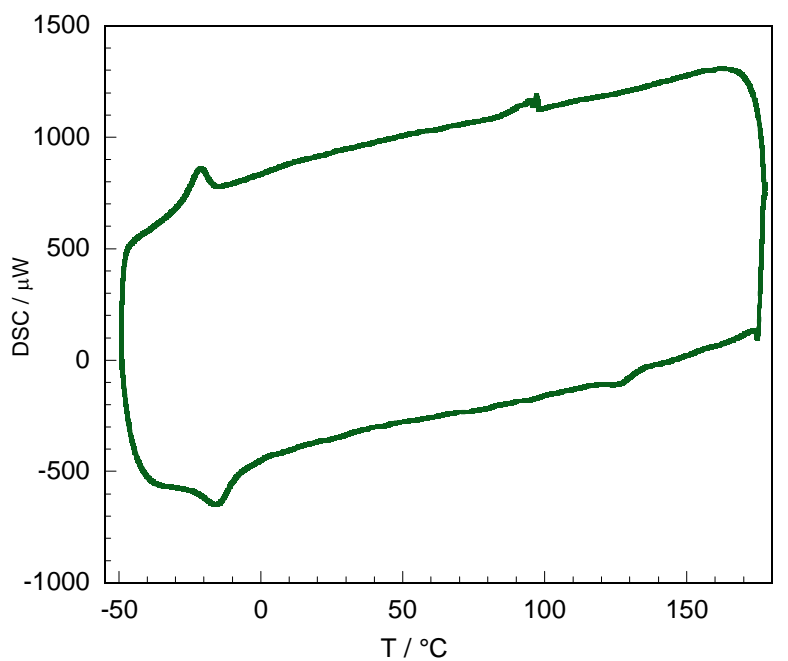

Figure S5. DSC trace of of 3.

\section{XRDs and UV-vis spectra of thin films}

Instruments. X-ray diffractions (XRDs) of thin films fabricated on the $\mathrm{Si} / \mathrm{SiO}_{2}$ substrate were

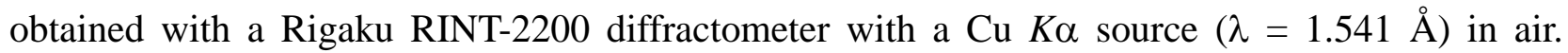
UV-vis spectra of the spin-coated thin films on quartz substrates were recorded on a Shimadzu UV-3100 spectrometer. 
From the XRD pattern of the thin film annealed at $150{ }^{\circ} \mathrm{C}$, the interlayer distance ( $d$-spacing) was estimated to be ca $25 \AA$, which is longer than molecular length (trans-trans isomer, $16.4 \AA$ for the $\pi$-skeleton, $21 \AA$ for the alkyl chain part) in the optimized structure by MOPAC-PM3 calculation (Figure S6). Therefore, we speculated that in the annealed thin film $\mathbf{3}$ takes interactive dimer, which is a repeating-unit in the layer structure. A similar structure was reported for the related thienoquinoid trimer. ${ }^{\mathrm{S}}$

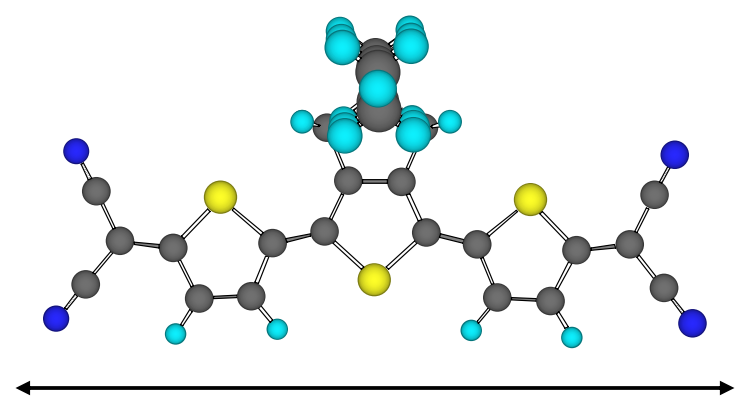

ca. $16.4 \AA$

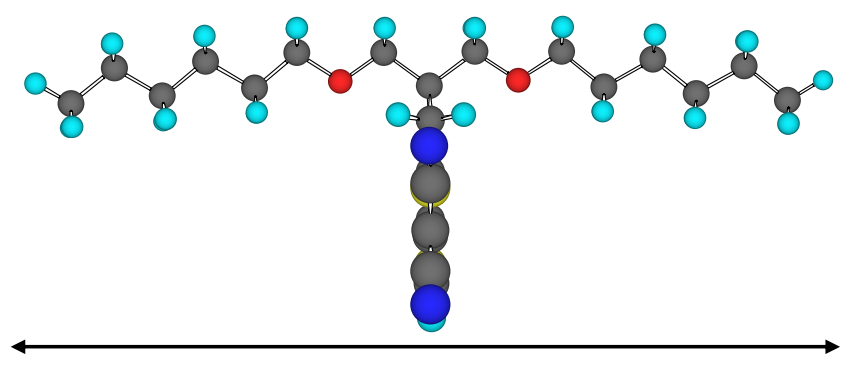

ca. $21 \AA$

Figure S6. MOPAC-PM3-optimized structure of 3.

\section{Device fabrication and evaluation}

Fabrication of the OFETs was carried out at ambient conditions without taking any precautions to isolate from ambient oxygen, moisture or light. The devices were fabricated on a heavily doped $n^{+}$-Si (100) wafer with a $200 \mathrm{~nm}$ thermally grown $\mathrm{SiO}_{2}\left(C_{i}=17.3 \mathrm{nF} \mathrm{cm}{ }^{-2}\right)$ as the gate dielectric. The $\mathrm{SiO}_{2}$ surface was modified with an OTS (octyltrichlorosilane) SAM (self-assembled monolayer) by immersing the $\mathrm{Si} / \mathrm{SiO}_{2}$ substrate in $1 \mathrm{mM}$ OTS in toluene at room temperature for $24 \mathrm{~h}$. A semiconductor layer was first deposited on the OTS-modified $\mathrm{SiO}_{2}$ substrate by spin-coating a $0.4 \mathrm{wt} \%$ solution of 3 in chloroform at $2000 \mathrm{rpm}$ for $30 \mathrm{sec}$, and dried in air. Before deposition of source and drain electrode films were thermally annealed at 50,100, 150, or $200{ }^{\circ} \mathrm{C}$ for 30 min under argon atmosphere.

On top of the organic thin film, gold films (ca. $80 \mathrm{~nm}$ ) as drain and source electrodes were vacuum-deposited through a shadow mask (back pressure: $\sim 1 \times 10^{-4} \mathrm{~Pa}$ ). The drain-source channel length $(L)$ and width $(W)$ are $50 \mu \mathrm{m}$ and ca. $1.5 \mathrm{~mm}$, respectively. Characteristics of the OFET devices were measured at room temperature in air with a Keithly 6430 subfemtoammeter and a Keithly 2400 source meter, operated by a LabTracer program and GPIB interface. The field-effect mobility $\left(\mu_{\mathrm{FET}}\right)$ was calculated in the saturation regime of the $I_{d s}$ using the equation, $I_{d}=\left(W \mathrm{C}_{\mathrm{i}} / 2 L\right)$ $\mu_{\text {FET }}\left(V_{g}-V_{\text {th }}\right)^{2}$, where $C_{i}$ is the capacitance of the $\mathrm{SiO}_{2}$ insulator, $V_{g}$ and $V_{\text {th }}$ are the gate and threshold voltages, respectively. Current on/off ratio $\left(I_{o n} / I_{\text {off }}\right)$ was determined from the $I_{d}$ at $V_{g}=0$ 
$\mathrm{V}\left(I_{\text {off }}\right)$ and $V_{g}=60 \mathrm{~V}\left(I_{o n}\right)$, unless otherwise stated. The data summarized in Table 1 are typical device characteristics obtained from ca. 10 devices. Table S1 summarized the device characteristics of 12 individual devices (anneal temperature: $150{ }^{\circ} \mathrm{C}$ ) to check the reproducibility. In addition, Figure $\mathrm{S} 7$ shows device characteristics as a function of storage days.

Table S1. FET characteristics of 3-based OFETs annealed at $150{ }^{\circ} \mathrm{C}$.

\begin{tabular}{lll}
\hline$\# 1$ & $\mu_{\text {FET }} / \mathrm{cm}^{2} \mathrm{~V}^{-1} \mathrm{~s}^{-1}$ & $I_{\text {on }} / I_{\text {off }}$ a \\
\hline 1 & $0.091 \pm 0.004$ & $\sim 10^{4}$ \\
2 & $0.14 \pm 0.04$ & $\sim 10^{4}$ \\
3 & $0.11 \pm 0.01$ & $\sim 10^{4}$ \\
4 & $0.18 \pm 0.04$ & $\sim 10^{4}$ \\
5 & $0.17 \pm 0.05$ & $\sim 10^{4}$ \\
6 & $0.10 \pm 0.01$ & $\sim 10^{4}$ \\
7 & $0.075 \pm 0.003$ & $\sim 10^{5}$ \\
8 & $0.13 \pm 0.01$ & $\sim 10^{5}$ \\
9 & $0.16 \pm 0.01$ & $\sim 10^{5}$ \\
10 & $0.23 \pm 0.07$ & $\sim 10^{4}$ \\
11 & $0.13 \pm 0.01$ & $\sim 10^{3}$ \\
12 & $0.10 \pm 0.01$ & $\sim 10^{3}$ \\
\hline
\end{tabular}

a) The values are the maximum $I_{\text {on }} / I_{\text {off }}$, where $I_{\text {off }}$ was the minimum in the transfer plots.

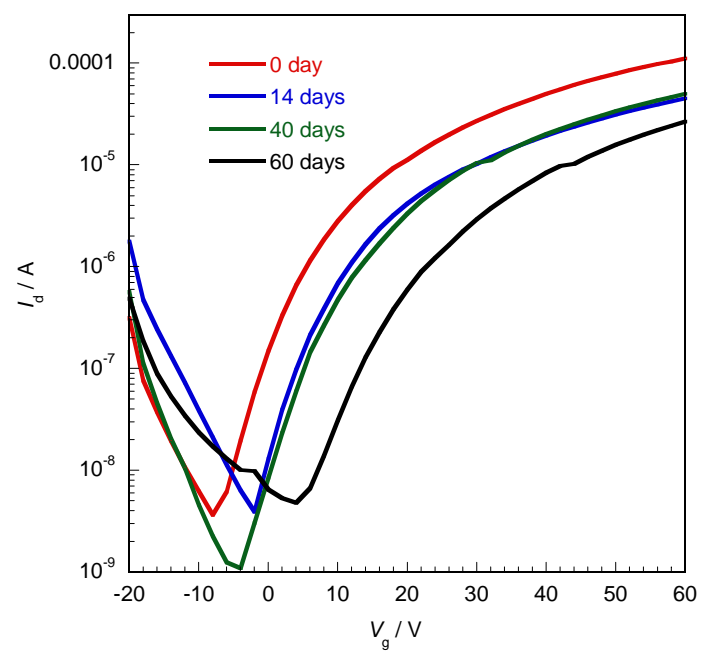

Figure S7. Transfer characteristics of 3-based devices measured at 14, 40, and 60 days after fabrication. The devices were stored in plastic boxes under the ambient conditions. Mobility extracted from the transfer characteristic are 0.16 (0 day), 0.07 (14, 40 days), and $0.01 \mathrm{~cm}^{2} \mathrm{~V}^{-1} \mathrm{~s}^{-1}$ (60 days). 


\section{References}

S1. Izumi, T.; Kobashi, S.; Takimiya, K.; Aso, Y.; Otsubo, T. J. Am. Chem. Soc. 2003, 125, 5286-5287.

S2. Uno, M.; Seto, K.; Takahashi, S. J. Chem. Soc., Chem. Commun. 1984, 932-933.

S3. Takahashi, T.; Matsuoka, K.; Takimiya, K.; Otsubo, T.; Aso, Y. J. Am. Chem. Soc. 2005, 127, 8928-8929.

S4. (a) Brédas, J.-L.; Silbey, R.; Boudreaux, D. S.; Chance, R. R. J. Am. Chem. Soc. 1983, 105, 6555-6559. (b) Pommerehne, J.; Vestweber, H.; Guss, W.; Mark, R. F.; Bässler, H.; Porsch, M.; Daub, J. Adv. Mater. 1995, 7, 551-554.

S5. (a) Pappenfus, T. M.; Chesterfield, R. J.; Frisbie, C. D.; Mann, K. R.; Casado, J.; Raff, J. D.; Miller, L. L. J. Am. Chem. Soc. 2002, 124, 4184-4185. (b) Chesterfield, R. J.; Newman, C. R.; Pappenfus, T. M.; Ewbank, P. C.; Haukaas, M. H.; Mann, K. R.; Miller, L. L.; Frisbie, C. D. Adv. Mater. 2003, 15, 1278-1282. 